\title{
Crimes ambientais contra a fauna: táxons cinegéticos registrados no período de 2007 a 2015 na área de proteção ambiental de Guaratuba, Paraná e seu entorno
}

A caça de animais silvestres é uma atividade ilegal que ocorre em todas as regiões do Brasil, exercida por diferentes populações. O presente artigo teve por objetivo contribuir para o conhecimento dos táxons cinegéticos na Área de Proteção Ambiental de Guaratuba e seu entorno, no período de 2007 a 2015 . A pesquisa é caracterizada como documental. Para a coleta de dados foram utilizados os Boletins de Ocorrência (BO) de crimes contra a fauna registrados pela Polícia Militar Ambiental do Estado do Paraná, tendo a mesma durado entre março de 2016 a fevereiro de 2017. Após a análise dos dados pode-se observar que, no que tange as espécies alvos de caça ilegal citadas nos boletins foram identificados nos seguintes grupos $62,64 \%$ mamíferos, seguidos de $36,26 \%$ aves e $1,1 \%$ répteis. Entre os mais citados estão: Dasypodidae, Procyonidae e Tayassuidae. Do grupo das aves, Tinamídea Turdidae e Ramphastidae. Já as aves menores geralmente canoras, são as mais apanhadas e tem como destino o comércio ilegal e cativeiro. Além disso, a caça apresenta características de caça esportiva e comercial associada ao porte irregular de arma de fogo (espingarda) e petrechos. O cenário se mostrou preocupante em relação as suas potenciais implicações ecológicas, ilustrando que além de ser uma prática de caça ilegal e indiscriminada, tem sido realizada dentro de fragmentos preservados pelas UC que na maioria das localidades possuem uma precária fiscalização e poucos incentivos.

Palavras-chave: Fauna; Floresta Atlântica; Conservação; Caça.

\section{Environmental crimes against fauna: game taxa recorded from 2007 to 2015 in the environmental protection area of Guaratuba, Paraná and its surroundings}

\begin{abstract}
The hunting of wild animals is an illegal activity that occurs inall regions of Brazil, exercised by different populations. Thisarticle aimed to contribute to the knowledge of thesynergetic taxa in the Environmental Protection Area of Guaratuba and your surroundings, in the period from 2007 to 2015. The research is characterized as documentary. Fordata collection were used the Occurrence (BO) of crimes against fauna recorded by the Environmental military police of Paraná State, which lasted from march to february 2016 to 2017. After the analysis of the data it can be observed that in the target species of poaching cited in the newsletters were identified in the following groups $62.64 \%$ mammals, followed by $36.26 \% 1.1 \%$ reptiles and birds. Among the mosthunted Dasypodidae, Procyonidae and Tayassuidae. The group of birds, Tinamídea, Turdidae and Ramphastidae. The smaller birds, song birds are the most commonly caught and has targeted the ilegal trade and captivity. In addition, the hunting sport and hunting features associated with irregular sized comercial firearm (rifle) and fitting equipment. The scenario showed concern about their potential ecological implications, illustrating that in addition to be a practice illegal and indiscriminate hunting, has been held in fragments preserved by UC that most towns have a precarious and few incentives.
\end{abstract}

Keywords: Faun; Atlantic Forest; Conservation; Hunting.

Topic: Desenvolvimento, Sustentabilidade e Meio Ambiente

Reviewed anonymously in the process of blind peer.

\section{Elaine Paduch}

Universidade Federal do Paraná, Brasil

http://lattes.cnpq.br/6913225388226362

paduch.elaine@gmail.com

Juliana Quadros (iD

Universidade Federal do Paraná, Brasil

http://lattes.cnpq.br/6808343383154097

http://orcid.org/0000-0002-2176-5497

quadros.juliana@hotmail.com
Received: 10/06/2018

Approved: 24/07/2018
Referencing this:

PADUCH, E.; QUADROS, J.. Crimes ambientais contra a fauna: táxons cinegéticos registrados no período de 2007 a 2015 na área de proteção ambiental de Guaratuba, Paraná e seu entorno. Revista Ibero Americana de Ciências Ambientais, v.9, n.5, p.258-271, 2018. DOI: http://doi.org/10.6008/CBPC2179-6858.2018.005.0023 
Crimes ambientais contra a fauna: táxons cinegéticos registrados no período de 2007 a 2015 na área de proteção ambiental de Guaratuba,

\section{INTRODUÇÃO}

A Floresta Atlântica é uma das florestas tropicais com maior grau de diversidade biológica do planeta, resultante de um quadro evolutivo de variações geológicas, e alterações climáticas condições geoclimatológicas e evolução biológica demasiadamente complexo. Este isolamento propiciou à evolução natural das espécies e a possibilidade de endemismo, existem cerca de 8.000 espécies endêmicas. Em virtude da diversidade de espécies e níveis de ameaça, a Floresta Atlântica é um dos 25 hotspots mundiais o que a torna uma área prioritária para a conservação de biodiversidade (MYERS et al., 2000; MITTERMEIER et al., 2004). Atualmente restam cerca de $7 \%$ da área original da Floresta Atlântica, considerando os fragmentos acima de 100 hectares, que perfazia cerca de $1.350 .000 \mathrm{~km}^{2}$ do território nacional. Além disso, é a região onde se encontram os maiores contingentes populacionais humanos mais de $60 \%$ da população brasileira.

A devastação da Mata Atlântica é resultante do processo de ocupação e os sucessivos ciclos de exploração de seus recursos florestais que levaram a uma drástica redução da cobertura vegetal (DEAN, 1996). A perda e a fragmentação de habitats são os principais fatores de redução direta e indireta da fauna, razão pela qual inúmeras espécies encontram-se ameaçadas de extinção (MMA, 2002; TABARELLI et al., 2005; SILVA et al., 2005).

As perdas expressivas da cobertura vegetal associada a práticas de exploração como a caça e extrativismo são responsáveis pelo desequilíbrio do ecossistema florestal e influenciam na persistência de populações faunísticas nos remanescentes florestais. Como testemunho, a caça é uma atividade exercida por diferentes populações em diversas regiões das florestas tropicais (CULLEN et al., 2000).

Com a promulgação da Lei de Proteção à Fauna (Lei Federal n 5.197 de 1967) a caça foi considerada uma atividade ilegal cujo o infrator estaria sujeito a multa e a prisão (BRASIL, 1967). Posteriormente, foi editada a Lei Federal n 7. 653 de 1988 tornando a caça um crime inafiançável. Contudo, em 1998 a Lei de Crimes Ambientais (Lei Federal $n^{\circ} 9.605$ de 1998), flexibilizou tornando os crimes ambientais passiveis de multas elevadas a crimes de baixo potencial ofensivo, cuja a pena seja inferior a três anos, podendo ser convertida em multas e prestação de serviços. Esta lei inseriu novas restrições como perseguição e coleta de produtos e subprodutos da fauna, conforme o Artigo 29, "é proibida a caça, perseguição, apanha ou coleta de produtos e subprodutos da fauna silvestre". Entretanto, a pratica de caça, ainda foi permitida em situações excepcionais como a de extrema necessidade para matar a fome do indivíduo (BRASIL, 1998). Contudo, a edição de uma lei, qualquer que seja a natureza de seus objetivos - proteger a diversidade biológica, o patrimônio histórico-cultural e os modos de vida das populações humanas que nela convivem não garante que tais objetivos sejam cumpridos.

O estudo de Peres (2000) para a Floresta Amazônica aponta que cerca de 23 milhões de animais silvestres são caçados anualmente. O mesmo autor afirma perda da biomassa de vertebrados, especialmente os de grande porte, está fortemente relacionada com a pressão de caça (PERES, 2000; PERES et al., 2003). Kent Redford em seu artigo 'A Floresta Vazia' de 1992 contribui para o entendimento de que a prática de caça conduz ao processo chamado de 'defaunação', ocasiona desequilíbrios na cadeia trófica, levando 
Crimes ambientais contra a fauna: táxons cinegéticos registrados no período de 2007 a 2015 na área de proteção ambiental de Guaratuba,

espécies à extinção. Assim, para Redford (1997), a preservação da floresta em sua essência (estrutura e composição) não garante a conservação da biota, evidenciando dessa forma, que é o equilíbrio ecossistêmico que está em risco.

A situação na Mata Atlântica é ainda mais grave, o efeito da caça em ambientes antropizados e fragmentados é severamente impactado em curto prazo. Conforme observado tanto por Redford (1992) quanto Chiarello (2000) o efeito da pressão de caça sobre a fauna é ainda mais preocupante nos fragmentos florestais, como na Floresta Atlântica, pois as populações são pequenas e isoladas o que as torna suscetíveis à extinção mesmo sob baixa pressão de caça. Isso deve-se ao fato de que o isolamento de populações pela fragmentação florestal limita as populações em seus movimentos (migração) e impedem que estas áreas sejam recolonizadas, assim como também pela ausência de fontes potenciais de fauna nativa possam recolonizar para estas áreas modificadas pela caça (CULLEN et al., 2000; CHIARELLO, 2000; PERES, 2000).

Considerando a região da Área de Proteção Ambiental de Guaratuba, litoral do Paraná, como um mosaico de fragmentos florestais imersos em uma matriz antropizada e a relevância da caça como atividade ilegal que potencialmente ameaça a conservação da biodiversidade na região, depreende-se a importância de compreender diversos aspectos da atividade cinegética praticada na APA de Guaratuba e entorno. Este trabalho tem como objetivo contribuir para contribuir para o conhecimento dos táxons cinegéticos da Área de Proteção Ambiental de Guaratuba, e seu entorno, no período de 2007 a 2015.

\section{MATERIAIS E MÉTODOS}

\section{Área de Estudo}

Localizada no Litoral Sul do Estado do Paraná, a Área de Proteção Ambiental de Guaratuba (Figura 1), é uma unidade de conservação de Uso Sustentável (SNUC, 2000). Apresenta aproximadamente 200 mil ha, que protege áreas correspondentes ao domínio Mata Atlântica que compõe o maior remanescente preservado do bioma do sul do país (PARANÁ/IAP, 2006). Tem por objetivo compatibilizar o uso racional dos recursos naturais da região e a ocupação ordenada do solo, bem como garantir a qualidade de vida da população local (PARANÁ, 1992). Circunda a Baía de Guaratuba onde deságua um importante sistema fluvial e o abastecimento hídrico de seis municípios: Guaratuba (65,61\% do território da APA), seguido por São José dos Pinhais (11,25\%), Tijucas do Sul (9,24\%), Morretes (6,43\%), Paranaguá (5,69\%) e Matinhos $(1,78 \%)$.

Duas importantes bacias hidrográficas drenam a região, a bacia litorânea - a leste e a bacia do Alto Iguaçu - a oeste. Entre os mais importantes os rios estão: Sagrado, Cubatãozinho, Canavieiras, Arraial e São João (formadores do rio Cubatão), São Joãozinho (paralelo à BR-376). Há duas grandes represas: Vossoroca e Guaricana, ambas da Companhia Paranaense de Energia Elétrica - COPEL (SILVEIRA, 2005; PARANÁ/IAP, 2006).

Por estar localizado em uma região de Mata Atlântica, possui características peculiares o que reforça a sua importância para com a conservação e tornam-se prioritárias para a formação de corredores ecológicos na Mata Atlântica. Dessa forma, foram criadas outras quatro unidades de conservação de Proteção Integral 
Crimes ambientais contra a fauna: táxons cinegéticos registrados no período de 2007 a 2015 na área de proteção ambiental de Guaratuba,

na categoria parque (SNUC, 2000), sendo o Parque Nacional de Saint-Hilaire/Lange $(24.267,914$ ha) e o Parque Nacional Guaricana (49.286,87 ha); são gerenciadas pelo ICMBio. O Parque Estadual do Boguaçú (6.052ha) e o Parque Municipal Lagoa do Parado (PARANÁ/IAP, 2006).

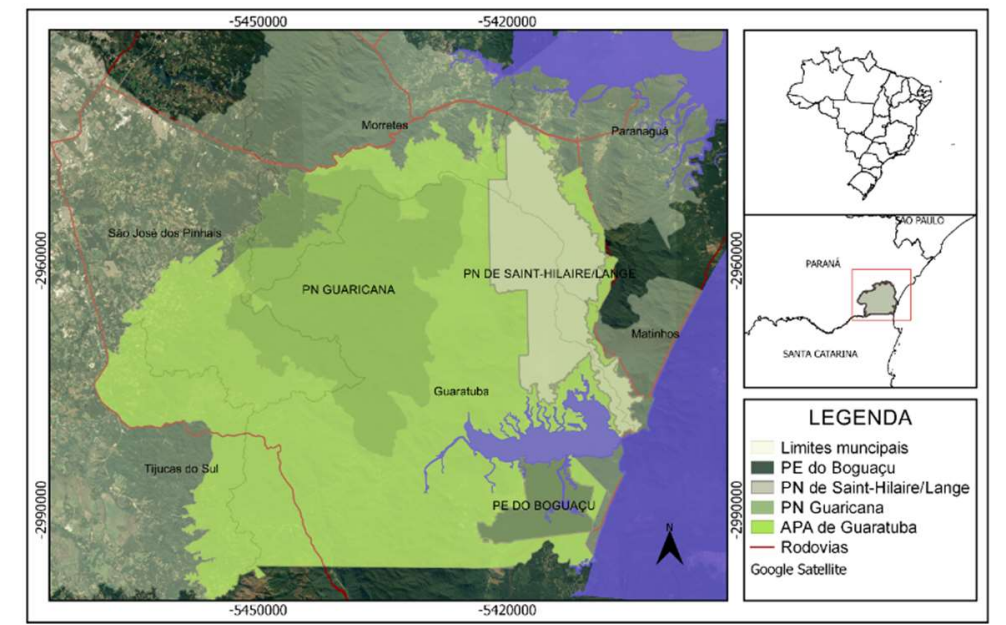

Figura 1: localização da APA de Guaratuba e dos parques situados na APA, litoral do paraná.

Os principais acessos: a BR-376, que é o principal eixo rodoviário que liga Curitiba à Florianópolis; a BR-277, que possui intenso tráfego de caminhões, sendo a via de acesso ao Porto Dom Pedro II em Paranaguá, o segundo maior porto graneleiro da América Latina; a PR-508, que liga a BR-277 aos municípios balneários de Matinhos e Guaratuba e constitui via alternativa à BR-376 para acesso a Santa Catarina. A PR508 margeia o PNSHL na sua face leste. A estrada não-pavimentada da Limeira atravessa a APA no sentido norte-sul passando entre os Parques, Parque Nacional Guaricana e Parque Nacional de Saint-Hilaire/Lange. Outras estradas rurais que cortam a APA, acesso via terrestre para várias pequenas comunidades rurais (PARANÁ/IAP, 2006).

A Serra da Prata, uma importante cadeia de montanhas pertencente à Serra do Mar é protegida pelo Parque Nacional de Saint-Hilaire/Lange o entorno do Parque Nacional Guaricana, o Parque Estadual do Boguaçú protege regiões de manguezais e sítios arqueológicos na planície e o Parque Natural Municipal Lagoa do Parado. No entanto, nenhuma delas possui plano de manejo, sendo este o maior desafio da gestão atualmente (PARANÁ/IAP, 2006). A região de extrema relevância biológica possui ecossistemas únicos, regiões íngremes como morros, serras e picos; e as áreas correspondentes aos mananciais e recursos hídricos como unidades de proteção especial segundo enquadramento ambiental do zoneamento da APA de Guaratuba (PARANÁ/IAP, 2006).

A Floresta Ombrófila Densa de terras baixas e Floresta Ombrófila Densa Aluvial compreende as formações florestais distribuídas sobre as planícies de acumulação de sedimentos dos rios que deságuam na região litorânea, sujeitas ou não a inundações periódicas. A formações de Floresta Ombrófila Densa Submontana que ocupam a planície litorânea e o início das encostas da serra do mar. As formações de Floresta Ombrófila Densa Montana que abrangem áreas intermediárias das encostas da serra do Mar e Ombrófila Densa Alto Montana nas porções mais elevadas da Serra do mar. Abrange ainda as formações 
Crimes ambientais contra a fauna: táxons cinegéticos registrados no período de 2007 a 2015 na área de proteção ambiental de Guaratuba,

florestais da Floresta Ombrófila é uma unidade fitoecológica onde contempla-se a coexistência de representantes das floras tropical (afro-brasileira) e temperada (austro-brasileira), em marcada relevância fisionômica de elementos Coniferales e Laurales, onde domina Araucaria angustifólia (RODERJAN, et al. 2002).

Conforme o respectivo Zoneamento a APA, possui ainda em zonas de ocupação intensa e agrícola com o uso inadequado das áreas de produção agrícolas com o cultivo com agroquímicos e pulverizações aéreas, o adensamento das ocupações e a expansão das urbanas (PARANÁ/IAP, 2006). Encontram-se outras duas áreas afetada por empreendimentos hidrelétricos, além disso, o estudo de Silveira (2005) apontou pressão antrópica exercida sobre seus ecossistemas em áreas sensíveis como áreas de preservação, margens de rios e encostas associados às práticas inadequadas de exploração de recursos e de maneira insustentável resulta na degradação dos recursos. Seja pela mineração, atividades ilegais de caça e o extrativismo os significativos impactos ocasionados por atividades econômicas presentes neste território.

\section{Coleta e análise de dados}

A coleta de dados ocorreu de março de 2016 a fevereiro de 2017. A técnica utilizada na pesquisa consistiu na análise documental (GODOY, 1995; BAUER et al., 2008) dos Autos de Infração Ambiental (AIA Boletins de Ocorrência) emitidos no âmbito estadual para crimes ambientais contra a fauna, de acordo com o Artigo 29 da Lei de Crimes Ambientais n 9.605 de 13 de fevereiro de 1998, na região da Área de Proteção Ambiental de Guaratuba, para o período de 2007 a 2015. acompanhado do auto de apreensão de animais e depósito subprodutos da fauna, objetos da infração como: instrumentos, petrechos, equipamentos ou veículos de qualquer natureza utilizados na infração, conforme o Decreto $n^{\circ} 6.514$ de 2008 em seu artigo $3^{\circ}$.

Os dados foram organizados em planilhas no programa Microsoft Excel versão 2016. Para a análise dos dados foram aplicados métodos estatísticos descritivos. Para a identificação das espécies alvo, estratégias utilizadas pelos caçadores e locais de ocorrência de caça foi realizada a descrição qualitativa das informações trazidas pelos boletins de ocorrência.

As categorias de crimes contra a fauna utilizadas na sistematização dos dados e análises são as aquelas dos boletins de ocorrência, quais sejam: 'matar (ou abater)', 'apanhar, perseguir e transportar' e 'manter em cativeiro'. O registro dos táxons e quantidades de indivíduos foram obtidos dos boletins de ocorrência a partir dos nomes vernaculares, chegando ao menor nível taxonômico sempre que possível. E, quando não, foram agrupados em níveis taxonômicos supra específicos. Os referenciais para taxonomia dos grupos registrados foram: para as aves, o Comitê Brasileiro de Registros Ornitológicos (CBRO, 2014); e para mamíferos foi consultado o Livro Mamíferos do Brasil (REIS et al., 2006). Para averiguar o status de conservação dos táxons no Estado do Paraná foi utilizado o Decreto 7264/2010; no Brasil, a Portaria MMA n 444/2014; e em nível internacional, a Lista Vermelha (RedList) da International Union for Conservation of Nature (IUCN, 2017). 
Crimes ambientais contra a fauna: táxons cinegéticos registrados no período de 2007 a 2015 na área de proteção ambiental de Guaratuba,

\section{RESULTADOS}

Entre 2007 e 2015 foram registradas 435 ocorrências de crimes contra a fauna, sendo que as ocorrências de apreensão de fauna em cativeiro predominam na amostra, com $72,64 \%$ do total. 0 crime de matar (abate) corresponde a 12,64\%, a apanha 9,43\%, o transporte a 3,91\% e a perseguição a 1,38\% (Tabela 1).

Tabela 1: número de ocorrências registradas entre 2007 e 2015, de crimes contra a fauna (caça) na APA de Guaratuba, Paraná.

\begin{tabular}{|c|c|}
\hline Crimes contra a Fauna & Número de ocorrências \\
\hline Abate & 55 \\
\hline Apanha & 41 \\
\hline Transporte & 17 \\
\hline Perseguição & 6 \\
\hline Cativeiro & 316 \\
\hline Total & 435 \\
\hline
\end{tabular}

\section{Crimes contra a fauna: matar}

Para o crime de matar ou abater, foram registrados nos boletins de ocorrência 91 espécimes distribuídos em 23 gêneros e 17 famílias de mamíferos ( $n=57 / 62,64 \%$ ), aves ( $n=33 / 36,26 \%$ ) e répteis ( $n=1$ / 1,1\%). Quanto aos mamíferos, foram registrados 10 gêneros distribuídos em nove famílias, com destaque para Dasypodidae (tatus), Procyonidae (quatis) e Tayassuidae (porcos do mato) (Figura 2a). Houve um registro de abate de uma espécie exótica invasora Sus scrofa (javali) e em uma das ocorrências não foi possível identificar a espécie pois na descrição do boletim de ocorrência consta apenas "6 kg de carne de caça". A Figura 3, mostra um macaco prego (Sapajus nigritus) abatido por caçadores e preparado para consumo humano. Os caçadores foram encontrados praticando caça esportiva e de lazer na Estrada que dá acesso à localidade do Parati, nas imediações do Parque Nacional de Saint-Hilaire/Lange.

A avifauna também teve uma variedade significativa de espécies mortas, sendo representadas por 11 gêneros distribuídos em oito famílias com destaque Tinamidae (macucos, inhambus, jaós, codornas) e Turdidae (sabiás) (Figura 2b). O grupo dos répteis teve apenas um registro, da família Teiidae, a espécie Salvator merianae (Teiu açu).

a

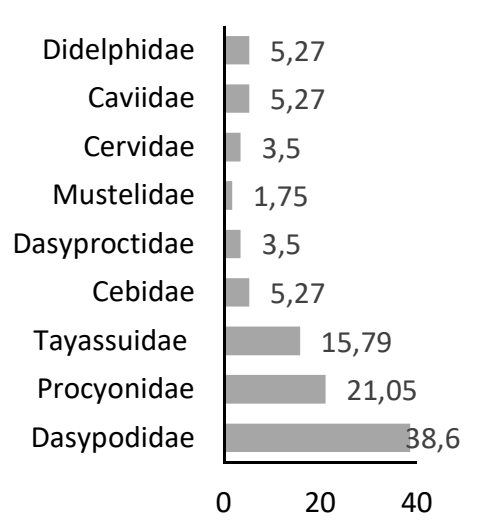

b

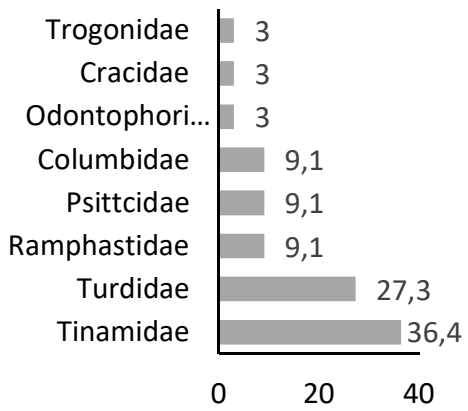

Percentual de indivíduos abatidos (\%)

Figura 2: famílias de mamíferos (a) e aves (b) abatidos APA de Guaratuba e entorno no período de 2007 e 2015. 


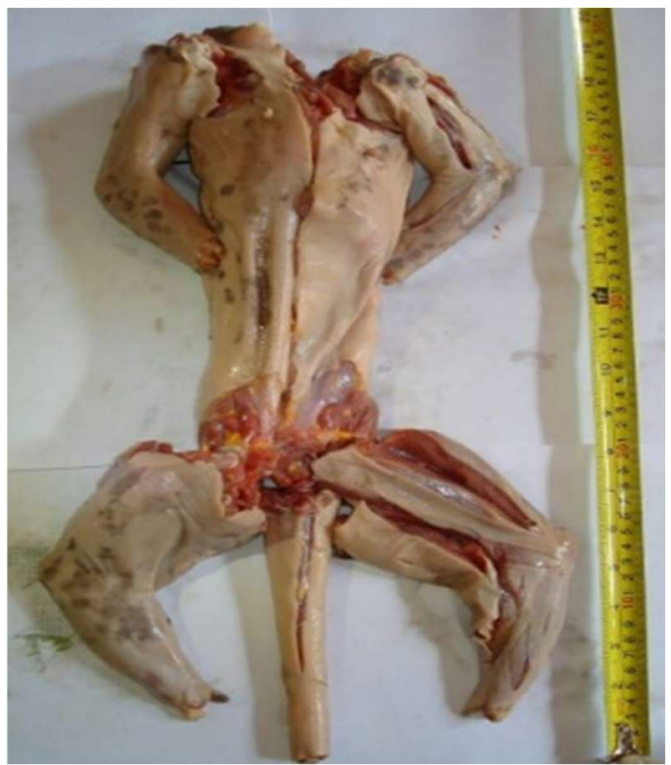

Figura 3: macaco prego (sapajus nigritus) abatido e preparado para consumo no entorno do parque nacional de sainthilaire/lange, APA e Guaratuba, litoral do Paraná. Fonte: Quadros (2016).

\section{Crimes contra a fauna: apanha, perseguição e transporte}

Os crimes de apanha, perseguição e transporte incidem especialmente sobre as aves, e entre estas preferencialmente as canoras. Foram registradas 13 espécies distribuídas em seis famílias, com destaque para Thraupidae e Emberizidae. Do total de indivíduos identificados ( $n=144$ ), 41,67\% são Coleiros da espécie Sphorophila caerulescens e 23,61\% são Trinca Ferros da espécie Saltator similis (Tabela 2).

Tabela 2: apanha, perseguição e transporte de aves, na APA de Guaratuba e entorno, entre 2007 e 2015.

\begin{tabular}{|c|c|c|c|c|}
\hline Família & Nome científico & Nome vernacular & $\mathbf{N}^{\circ}$ de indivíduos & Percentual (\%) \\
\hline Emberizidae & Sphorophila caerulescens & Coleiro & 60 & 41,67 \\
\hline \multirow[t]{6}{*}{ Thraupidae } & Saltator similis & Trinca Ferro & 34 & 23,61 \\
\hline & Sicalis flaveola & Canário da Terra & 12 & 8,33 \\
\hline & Tangara seledon & Saíra Sete Cores & 12 & 8,33 \\
\hline & Sporophila frontalis & Pixoxó & 6 & 4,17 \\
\hline & Sporophila plumbea & Patativa & 3 & 2,08 \\
\hline & Sporophila angolensis & Curió & 5 & 3,47 \\
\hline Subtotal & - & - & 72 & 50,00 \\
\hline Turdidae & Turdus sp. & Sabiá & 4 & 2,78 \\
\hline Ramphastidae & Ramphastos sp. & Tucano & 3 & 2,08 \\
\hline \multirow[t]{2}{*}{ Fringillidae } & Spinus magellanicus & Pintassilgo & 2 & 1,39 \\
\hline & Euphonia violacea & Gaturamo Verdadeiro & 1 & 0,69 \\
\hline Subtotal & - & - & 3 & 2,08 \\
\hline \multirow[t]{2}{*}{ Psitacidae } & Amazona sp. & Papagaio & 1 & 0,69 \\
\hline & Brotogeris tirica & Periquito & 1 & 0,69 \\
\hline Subtotal & - & - & 2 & 1,38 \\
\hline Total & - & - & 144 & 100 \\
\hline
\end{tabular}

\section{Crimes contra a fauna: manter em cativeiro}

A avifauna foi o grupo mais representativo para o crime contra a fauna, de guardar ou manter em cativeiro ou depósito. Foram apreendidas 1.075 gaiolas e 2.780 aves, incluindo canários belga, exóticos; e os chamados 'pintagóis' que são resultado do cruzamento entre Pintassilgo e Canários Belga. Para os mamíferos foram três espécies tidas em cativeiro: capivara Hydrochaerus hydrochaeris $(n=2)$, macaco prego Sapajus 
Crimes ambientais contra a fauna: táxons cinegéticos registrados no período de 2007 a 2015 na área de proteção ambiental de Guaratuba,

nigritus ( $n=5$ ) e sagui de tufos pretos Callithrix penicillata $(n=1)$, considerada uma espécie exótica na área de estudo (Tabela 3).

Tabela 3: espécimes de aves e mamíferos mantidos em cativeiro na APA de Guaratuba e entorno, entre 2007 e 2015.

\begin{tabular}{|l|l|l|}
\hline Grupos & & $\mathbf{N}^{\circ}$ de indivíduos \\
\hline \multirow{4}{*}{ Aves } & Silvestres identificadas & 1415 \\
\cline { 2 - 3 } & Silvestres não identificadas & 1337 \\
\cline { 2 - 3 } & Canário Belga e Pintagol & 29 \\
\hline \multirow{2}{*}{ Mamíferos } & Capivara & 2 \\
\cline { 2 - 3 } & Macaco Prego & 5 \\
\hline & Sagui de tufos pretos & 1 \\
\hline Total & & 2788 \\
\hline
\end{tabular}

Foram identificadas 1.415 aves silvestres mantidas em cativeiro ilegalmente, as quais estão distribuídas em treze famílias e vinte e sete espécies. As pertencentes à família Thraupidae $(42,69 \%)$ e Emberizidae (34,63\%) foram as mais representadas, como observado no crime de apanha e em uma relação direta com este (Tabela 4). As espécies Coleiro Sporophila caerulescens (34,20\%), Canário da Terra Sicalis flaveola (18,37\%) e Trinca Ferro Saltator similis (9,12\%) foram as mais abundantes em cativeiro (Figura 4).

Tabela 4: número de indivíduos por família de aves mantidas em cativeiro na APA de Guaratuba e entorno, entre 2007 e 2015.

\begin{tabular}{|l|c|c|}
\hline FAMÍLIA & NÚMERO DE INDIVÍDUOS & \% \\
\hline Thraupidae & 604 & 42,69 \\
\hline Emberizidae & 490 & 34,63 \\
\hline Fringillidae & 98 & 6,93 \\
\hline Psitacidae & 98 & 6,93 \\
\hline Cardinalidae & 35 & 2,47 \\
\hline Turdidae & 76 & 5,37 \\
\hline Cracidae & 3 & 0,21 \\
\hline Columbidae & 2 & 0,14 \\
\hline Corvidae & 2 & 0,14 \\
\hline Cotingidae & 2 & 0,14 \\
\hline Estrildidae & 2 & 0,14 \\
\hline Ramphastidae & 2 & 0,14 \\
\hline Tinamiformes & 1 & 0,07 \\
\hline Total & 1415 & 100 \\
\hline
\end{tabular}

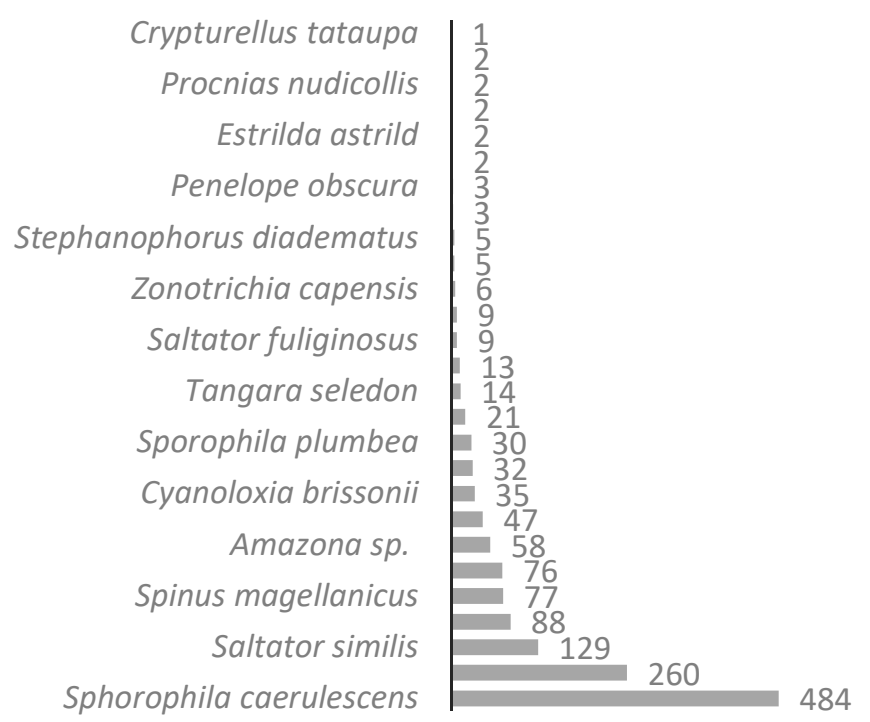

Figura 4: número de indivíduos de espécies de aves mantidas em cativeiro na APA de Guaratuba e entorno, entre 2007 e 2015 
Crimes ambientais contra a fauna: táxons cinegéticos registrados no período de 2007 a 2015 na área de proteção ambiental de Guaratuba,

Destas, quatro espécies encontram-se na lista nacional oficial de espécies ameaçadas de extinção: Coleiro (Sphorophila caerulescens), Curió (Sporophila angolensis), Pintassilgo (Spinus magellanicus) e Pixoxó (Sporophila frontalis) que são vulneráveis (VU). O papagaio-da-cara-roxa (Amazona brasiliensis) deixou a categoria vulnerável para quase ameaçada (NT) recentemente devido aos esforços de conservação da espécie (ICMBio, 2017). E ainda, a araponga (Procnias nudicollis) é considerada vulnerável (VU) pela Lista Vermelha da IUCN (IUCN, 2017).

\section{Petrechos e outras artes de caça}

Os petrechos utilizados na captura e guarda em cativeiro são: pios ( $n=125)$, que são usados tanto no abate quanto para a captura viva de aves, os alçapões $(n=111)$ em geral são usados para a manutenção em cativeiro e as gaiolas caçadeiras $(n=8)$ conforme a Figura 5. As gaiolas caçadeiras são outra forma de atrair pássaros, o uso desta armadilha com um indivíduo já cativo, denominado 'chamariz', que é levado na gaiola para que cante na mata, exercendo efeito atrativo especialmente sobre machos em períodos e, em épocas reprodutivas através do canto. $\mathrm{O}$ aparelho (compact disc) com CD de gravações sonoras de pássaros é uma alternativa tecnológica para os pios estes registrados nos boletins de ocorrência, também são alguns dos petrechos de captura de aves.

Foram identificadas três técnicas de caça de mamíferos: caça com armas de fogo (em busca ativa ou em tocaia), caça com cachorro e caça com o uso de armadilhas. As técnicas podem ser utilizadas separadamente ou ainda com a combinação de duas ou mais, como por exemplo na caça com cachorros que usualmente é acompanhada do uso de arma de fogo. É comum o uso de armadilhas e cães para apanhar estas espécies, as duas técnicas foram registradas nos boletins. Os petrechos mais utilizados na captura são as armadilhas, que são colocadas em locais estratégicos como trilhas de passagem de animais iscadas com um alimento que serve de atrativo (ceva).

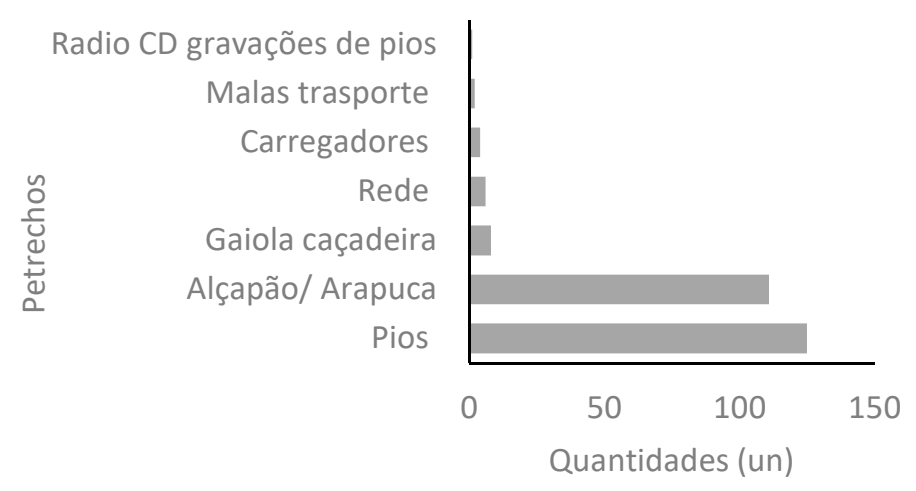

Figura 5: número de petrechos utilizados na captura de aves oriundas de apreensões, na APA de Guaratuba e entorno, entre 2007 e 2015.

\section{DISCUSSÃO}

A extinção de espécies tem sido atribuída ao desmatamento e a destruição de habitats (TABARELLI et al., 2005; SILVA et al., 2005). Na Floresta Atlântica as unidades de conservação foram criadas visando a 
Crimes ambientais contra a fauna: táxons cinegéticos registrados no período de 2007 a 2015 na área de proteção ambiental de Guaratuba,

proteção de espécies e ecossistemas, no entanto, a pressão de caça tem sido registrada inclusive dentro de unidades de conservação. O estudo de Chiarello (2000) no norte do Espirito Santo, demostrou que a caça ilegal ocorre sobre fragmentos de Mata Atlântica onde a presença de caçadores ilegais foi registrada em todas as áreas. Segundo o autor a prática de caça pode ser verificada tanto em áreas particulares como em reservas (UCS).

Para Peres (2003) a caça é um dos fatores que mais afeta a densidade dos recursos faunísticos, podendo até causar a extinção local, a remoção dos animais vertebrados implica em modificações profundas na estrutura e dinâmica de florestas tropicais, ou seja, a alteração profunda dos habitantes. Posto isso, a sobrevivência das espécies a longo prazo é incerta, pois as populações em fragmentos isolados, o que as torna suscetíveis à extinção mesmo sob baixa pressão de caça. Este fator tem sido o responsável pelo declínio de algumas espécies.

A análise dos dados demonstrou que a caça para o abate tem maior incidência em mamíferos de grande e médio porte (tatus, quati, porco-do-mato, veados e macacos) são os grupos preferenciais dos caçadores, corroborando com o estudo de Cullen et al. (2001). O estudo de Galletti et al. (2016) demonstrou que a caça é a causa da extinção de mamíferos silvestres no maior remanescente contínuo dessa floresta, na porção leste do estado de São Paulo. O autor indica que, onde a caça persiste causa a extinção local de algumas das espécies mais afetadas pela caça na região como a anta (Tapirus terrestris), bugio (Alouatta guariba), tatu-galinha (Dasypus novemcinctus) e algumas espécies de cervídeos (Mazama sp.). Outros estudos citaram o quati (Nasua) e o veado (Mazama americana), Tatu Mirim (Dasypus septemcinctus), Tatu de Rabo mole (Cabassous unicinctus), paca (Cuniculus paca), cutia (Dasyprocta prymnolopha) e a anta (Tapirus terrestris). Esses grandes mamíferos desempenham um papel fundamental na dispersão de sementes, na fertilização do solo e na renovação e equilíbrio ecossistêmico. Das espécies de aves alvo de caça registradas na APA, estão: o jacu e o Macuco e, constam na lista de ameaçadas de extinção, a Aburria jacutinga e o Tinamus solitarius, também são alvos de caçadores (MAZZOLLI et al., 2008).

No que diz respeito à pressão da caça sobre as espécies que não estão entre as preferencias, sabese que a caça afeta não somente a densidade das populações faunísticas, mas também a diversidade de espécies, isso porque a caça possui o efeito 'cascata', ou seja, provoca uma reação em cadeia, onde espécies do topo da cadeia alimenta são as mais afetadas. O estudo de Cullen et al. (2000) mostra a complexidade do tema e indica que a fragmentação da paisagem natural associado a impactos de caça afeta a quantidade e a qualidade do habitat disponível e, consequentemente a sobrevivência de espécies, especialmente as endêmicas e ameaçadas de extinção.

A caça está cada vez mais integrada ao mercado, agravando o processo de defaunação contemporânea, que está apenas começando a se concretizar (PERES, 2000). O estudo de Alves et al. (2010) no semiárido, Peres (2000) e Peres (2003) na Amazônia et al. (2004); Pereira et al. (2010) na floresta atlântica, apontaram que o desmatamento e o excesso de caça foram relatados como os principais motivos na redução dos animais em áreas de florestas locais. 
Crimes ambientais contra a fauna: táxons cinegéticos registrados no período de 2007 a 2015 na área de proteção ambiental de Guaratuba,

Os crimes contra a fauna estão previstos nos art. 29 a 35 da Lei de Crimes Ambientais - LCA (Lei 9.605/1998). Esta lei não legitima a legalização de qualquer tipo de caça. Isso significa dizer que a LCA restringe as modalidades de caça à: comercial, esportiva, temos ainda outras modalidades sendo: subsistência, controle e científica. De acordo com o Art. 37, não é considerado crime o abate de animal, quando realizado em estado de necessidade, ou seja, para saciar a fome do agente ou de sua família e também para caça controle proteger lavouras, pomares e rebanhos da ação predatória ou destruidora de animais devendo, portanto ser autorizado pela autoridade competente.

A utilização de armas de fogo incrementa o cenário da ilegalidade. O uso de espingarda era comum em comunidades rurais e, principalmente entre os que praticavam a caça. A recente obrigatoriedade do registro de posse de armas regulamentada pela Lei Federal № 11.706, de 19 de junho de $2008^{1}$, fez com que muitos caçadores tivessem mais uma restrição legal para a prática de caça, visto isso, os caçadores além de infringirem a lei de proteção à fauna também estão sujeitos a serem punidos pelo porte ilegal de armas.

O uso de armas de fogo para a pratica da caça envolve custos altos com a manutenção e munições. Pereira et al. (2010), indicaram que a caça por comunidades indígenas 'Tupinambás' quase não se utiliza de arma de fogo. Os Tupinambás preferem técnicas mais simples e de baixo custo. Este motivo também faz com que alguns caçadores prefiram comprar os alimentos para a subsistência, em vez de investir dinheiro com munições, uma vez que o animal pode ser capturado por outras técnicas, dependendo somente do esforço do caçador.

Além disso, na caça com armas não é possível selecionar a presa, o que não ocorre com a utilização da armadilha. Associado ao fato de a caça de subsistência ser seletiva, esta técnica é preferida porque não fere o animal, permitindo, no momento da captura, selecionar fêmeas ou machos. Se macho, o animal é abatido. Se fêmea, pode estar gestando ou com filhotes, por isso são soltas (PEREIRA et al., 2010). A caça com cães foi registrada nos trabalhos de Pianca (2004); Fernandes-Ferreira (2010); Vasconcelos-Neto et al., (2012). Segundo Koster (2008), esse tipo de estratégia garante retornos comparáveis ao uso de armas de fogo, sugerindo uma grande pressão de caça sobre espécies como os catetos (Tayassu pecari), queixadas (Pecari tajacu), tatus (Dasypus novencinctus e Dasypus septemcinctus) e aves de grande porte como inambú (Crypturellus sp.) e jacu (Penelope obscura). Isso justifica o porquê desta pratica ser considerada através do próprio termo 'amadorística', verifica-se que se trata de atividade desenvolvida por mero 'prazer' ou 'deleite' em matar criaturas vivas, o que por si só já se configura manifestamente como ato de crueldade e, portanto, como prática vedada pela Constituição Federal.

Outra questão refere-se comercialização da fauna, especialmente de aves canoras destinadas ao cativeiro. Os Boletins de ocorrência indicam que a principal finalidade desses animais é a comercialização,

\footnotetext{
${ }^{1}$ A utilização da espingarda requer o certificado de Registro de arma de fogo que é valido em todo o território nacional, o certificado autoriza o proprietário o porte regular de arma de fogo o qual deve manter exclusivamente em sua residência ou nas dependências deste, ou ainda em local de trabalho desde que ele seja o responsável pelo estabelecimento. Em outras situações o porte de ama só é permitido quando associada à caça de subsistência e, pela redação da Lei no 11.706/ 2008, o porte de armas é permitido aos residentes de áreas rurais, maiores de 25 (vinte e cinco) anos que comprovem depender do emprego de arma de fogo para prover sua subsistência alimentar familiar. Neste artigo também está especificado que o caçador para subsistência que der outro uso à sua arma de fogo, independentemente de outras tipificações penais, responderá, conforme o caso, por porte ilegal ou por disparo de arma de fogo de uso permitido.
} 
Crimes ambientais contra a fauna: táxons cinegéticos registrados no período de 2007 a 2015 na área de proteção ambiental de Guaratuba,

são destinados a residências particulares, utilizados como xerimbabos ou pets, sendo normalmente presos em gaiolas. A captura dessas espécies silvestres ocorre em áreas florestais próximas a áreas urbanas, estradas, trilhas e locais onde a presença de passeriformes é maior. Foram registrados nos boletins a captura de filhotes diretamente em seus ninhos. Conforme Ribeiro et al. (2007), o valor de comercialização é estipulado de acordo com a espécie, se raro o valor é mais alto, os machos são mais procurados, por apresentarem uma maior expressividade de canto e uma plumagem mais bonita. A captura de maior número de machos é um agravante para o equilíbrio populacional das espécies, uma vez que, cerca de $90 \%$ das espécies de aves adotam um comportamento monogâmico durante seu período reprodutivo.

Segundo o relatório da Rede Nacional de Combate ao Tráfico de Animais Silvestres (RENCTAS, 2001) o tráfico de animais silvestre a terceira maior atividade ilegal do mundo, perdendo apenas para o tráfico de armas e drogas. No Brasil, essa atividade ilegal movimenta cerca de 1,5 bilhões de dólares por ano e são retirados da natureza cerca de 38 milhões de animais anualmente. No Litoral Estado do Paraná é citado como local de captura e tráfico é o, na sua parcela de Mata Atlântica e manguezais. Dois municípios que compõem a APA de Guaratuba se destacam como áreas de tráfico de animais. Além do comércio em Paranaguá sendo destacado o mercado Municipal como ponto de venda de carne de caça, os animais movimentam o comércio ilegal nacional e internacional, especialmente de papagaios-de-cara-roxa (ANDRIGUETTO-FILHO et al., 1998).

\section{CONCLUSÕES}

O aumento da população urbana e a maior facilidade de acesso devido a fragmentação do continuum florestal por rodovias e estradas, e o uso de armas de fogo favorecem essa prática ilegal e aumentam seus impactos. A aplicação da legislação ambiental tem sido uma das formas de minimizar estes impactos. Entretanto, verifica-se que os crimes contra a fauna e contra a flora persistem, mesmo conhecendo os riscos de serem autuados e a proibição, os caçadores adentram as matas, para caçar.

Durante o estudo observou-se que, devido a dificuldades na fiscalização que geralmente é realizada com poucos recursos e efetivo policial insuficiente na maioria dos registros os infratores não são localizados e quando são as punições são leves. Há também uma carência uma categoria específica para a criminalização mais rigorosa no que diz respeito ao tráfico de animais silvestres que dificulta na atribuição de estes casos adequada à gravidade dos crimes, já que as penas são extremamente brandas, o que ocorre é um verdadeiro estímulo à reincidência destes crimes.

\section{REFERÊNCIAS}

ALVES, R. R. N.; MENDONÇA, L. E. T.; CONFESSOR, M. V. A.; VIEIRA, W. L. S.; VIEIRA, K. S.; ALVES, F. N.. Caça no Semiárido paraibano: uma abordagem etnozoologica. In: A etnozoologia no Brasil: importância, status atual e perspectivas. Recife: NUPEEA, 2010. p.349-377.

ANDRIGUETTO-FILHO, J. M.; KRÜGER, C. A.; LANGE, R. B. M. Caça, biodiversidade e gestão ambiental na Área de Proteção Ambiental de Guaraqueçaba. Revista Biotemas, Florianópolis, v.11, n.2, p.133-156, 1998.
BAUER, W. M.; GASKEL, G.. Pesquisa Qualitativa com texto, imagem e som. Petrópolis: Vozes, 2002.

BRASIL. Decreto no 4.340: Regulamenta artigos da Lei no 9.985, de 18 de julho de 2000, que dispõe sobre o Sistema Nacional de Unidades de Conservação da Natureza - SNUC, e dá outras providências. Brasília: DOU; MMA/SBF, 2002. 
BRASIL. Lei Federal $n^{\circ}$ 9.605: Dispõe sobre as sanções penais e administrativas derivadas de condutas e atividades lesivas ao meio ambiente, e dá outras providências. Brasília: DOU, 1998.

BRASIL. Lei $n^{\circ}$ 5.197: Dispõe sobre a proteção à fauna e dá outras providências. Brasília: DOU, 1967.

BRASIL. Lei no 9.985: Regulamenta o art. 225, § 1o, incisos I, II, III e VII da Constituição Federal, institui o Sistema Nacional de Unidades de Conservação da Natureza e dá outras providências. Brasília: DOU, 2000.

CBRO. Comitê Brasileiro de Registros Ornitológicos. Lista de aves do Brasil. 2014.

CHIARELLO, A. G.. Influência da caça ilegal sobre mamíferos e aves das matas de tabuleiro do norte do estado do Espírito Santo. Boletim do Museu de Biologia Mello Leitão, Santa Tereza, v.11, n.12, p.229-247, 2000.

CULLEN, L. J. R.; BODMER, R. E.; VALLADARES-PADUA, C.. Effects of hunting in habitat fragments of the Atlantic forest, Brazil. Revista Biological Conservation, v.95, n.1, p.49-56, 2000. DOI: https://doi.org/10.1016/S0006-3207(00)00011-2

DEAN, W.. A Ferro e Fogo: A História e a Devastação da Mata Atlântica Brasileira. São Paulo: Companhia das Letras, 1996.

FERNANDES-FERREIRA, H.. A caça no Brasil. Panorama histórico e atual. Tese (Doutorado em Ciências Biológicas) Universidade Federal da Paraíba, João Pessoa, 2010.

FUNDAÇÃO SOS MATA ATLÂNTICA \& INPE. Atlas dos remanescentes florestais da Mata Atlântica e ecossistemas

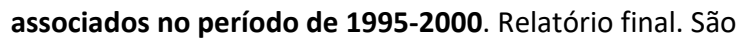
Paulo, 2002.

GALETTI, M.; BROCARDO, C. R.; BEGOTTI, R. A.; HORTENCI, L.; ROCHA-MENDES, F.; BERNARDO, C. S. S.; BUENO, R. S.; NOBRE, R.; BOVENDORP, R. S.; MARQUES, R. M.; MEIRELLES, F.; GOBBO, S. K.; BECA, G.; SCHMAEDECKE, G.; SIQUEIRA, T.. Defaunation and biomass collapse of mammals in the largest Atlantic forest remnant. Revista Animal Conservation, v.20, n.3, 2016. DOI: http://doi.org/10.1111/acv.12311

GODOY, S. A.. Pesquisa Qualitativa: Tipos Fundamentais. Revista de Administração de Empresas, São Paulo, v.35, n.3, 1995.

IUCN. Redlist of Threatened Species. Cambridge, 2017.

KOSTER, J. M.. The impact of hunting with dogs on wildlife harvests in the Bosawas Reserve, Nicaragua. Environmental Conservation, Cambridge, v.35, n.3, p.211-220, 2008. DOI: http://doi.org/10.1017/S0376892908005055

MAZZOLLI, M.; HAMMER, A. L. M.. Qualidade de ambiente para a onça-pintada, puma e jaguatirica na Baía de Guaratuba, Estado do Paraná, utilizando os aplicativos Capture e Presence. Revista Biotemas, Florianópolis, v.21, n.2, 2008.

MITTERMEIER, R. A.; Gil, P. R.; HOFFMANN, M.; PILGRIM, J. BROOKS, J.; MIITERMEIER, C. G.; LAMOURUX, J.; FONSECA,
G. A. B.. Hotspots Revisited: Earth's Biologically Richest and Most Endangered Terrestrial Ecoregions. Washington: Cemex, 2004.

MMA. Avaliação e identificação de áreas prioritárias para a conservação, utilização sustentável e repartição dos benefícios da biodiversidade dos biomas brasileiros. Brasília: MMA/SBF, 2002.

MYERS, N.; MITTERMEIER, R. A.; MITTERMEIER, C. G.; FONSECA, G. A. B.; KENT, J.. Biodiversity hotspots for conservation priorities. Revista Nature, n.403, p.853-858, 2000. DOI: http://doi.org/10.1038/35002501

PARANÁ. Decreto № 1.234. Curitiba: DOU, 1992.

PARANÁ/IAP. Plano de Manejo APA de Guaratuba, Curitiba, 2006.

PEREIRA, J. P. R.; SCHIAVETTI, A.. Conhecimentos e usos da fauna cinegética pelos caçadores indígenas 'Tupinambá de Olivença' (Bahia). Revista Biota Neotropica, v.10, n.1, p.175183, 2010.

PERES, C. A.. Effects of subsistence hunting on vertebrate community structure in Amazonian Forests. Revista Conservation Biology, v.14, p.240-253, 2000. DOI: http://doi.org/10.1046/j.1523-1739.2000.98485.x

PERES, C. A.; LAKE, I. R.. Extent of nontimber resource extraction in tropical forest: acessibility to game vertebrates by hunters in the Amazon. Conservation Biology, v.17, n.2, p.521-535, 2003.

PIANCA, C. C.. A caça e seus efeitos sobre a ocorrência de mamíferos de médio e grande porte em áreas preservadas de Mata Atlântica na Serra de Paranapiacaba, São Paulo. Dissertação (Mestrado em Ecologia de Agroecossistemas) Universidade de São Paulo, São Paulo, 2004.

REDFORD, K. H.. A floresta vazia. In: Manejo e Conservação de Vida Silvestre no Brasil. MCT-Cnpq/Sociedade Civil Mamirauá. Brasília, 1997. p.1-22.

REDFORD, K. H.. The Empty Forest. Revista Bioscience, Sacramento, v.42, n.6, p.412-422, 1992. DOI: http://doi.org/10.2307/1311860

RENCTAS. 1 Relatório Nacional sobre o Tráfico de Fauna Silvestre. Brasília, 2001.

RIBEIRO, L. B.; SILVA, M. G.. O comércio ilegal põe em risco a diversidade das aves no Brasil. Revista Ciência e Cultura, São Paulo, v.59, n.4, 2007.

RODERJAN, C. V.; GALVÃO, F.; KUNIYOSHI, Y. S.; HATSCHBACH, G. G.. As Unidades Fitogeográficas do Estado do Paraná, Brasil. Revista Ciência e Ambiente, Santa Maria, v.24, n.1, p.75-42, 2002.

SILVA, J. M. C.; CASTELETI, C. H.. Estado da biodiversidade da Mata Atlântica brasileira. In: State of the hotspots - Mata Atlântica: biodiversidade, ameaças e perspectivas. Conservação Internacional. Belo Horizonte, 2005. p.43-59. 
Crimes ambientais contra a fauna: táxons cinegéticos registrados no período de 2007 a 2015 na área de proteção ambiental de Guaratuba,

SILVEIRA, T. C.. Estudo das unidades ecodinâmicas da paisagem na APA de Guaratuba, PR. Subsídios ao planejamento ambiental. Dissertação (Mestrado em Geologia) - Universidade Federal do Paraná, Curitiba, 2005.

TABARELLI, M.; PINTO, L. P.; SILVA, C. M. J.; HIROTA, M. M.; BEDÊ L. C.. Desafios e oportunidades para a conservação da biodiversidade na Mata Atlântica brasileira. Revista Megadiversidade, São Paulo, v.1, n.1, 2005.

VASCONCELOS NETO, C. F. A.; SANTOS, S. S.; SOUSA, R. F.; FERNANDES-FERREIRA, H.; LUCENA, R. F. P.. A caça com cães (Canis lupus familiaris) em uma região do semiárido do nordeste do Brasil. Revista de Biologia e Farmácia, Paraíba, v.1, p.1-16, 2012.

A CBPC - Companhia Brasileira de Produção Científica (CNPJ: 11.221.422/0001-03) detém os direitos materiais desta publicação. Os direitos referem-se à publicação do trabalho em qualquer parte do mundo, incluindo os direitos às renovações, expansões e disseminações da contribuição, bem como outros direitos subsidiários. Todos os trabalhos publicados eletronicamente poderão posteriormente ser publicados em coletâneas impressas sob coordenação da Sustenere Publishing, da Companhia Brasileira de Produção Científica e seus parceiros autorizados. Os (as) autores (as) posteriormente ser publicados em coletâneas impressas sob coordenação da Sustenere Publishing, da Companhia Brasileira de Produção Cientifica e seus parce
preservam os direitos autorais, mas não têm permissão para a publicação da contribuição em outro meio, impresso ou digital, em português ou em tradução. 